Research Article

\title{
Birnbaum-Saunders Durability Life Prediction Model of Site-Exposed Concrete in the Saline Soil Area
}

\author{
Chenggong Lu $\mathbb{D},{ }^{1}$ Zhiqiang Wei, ${ }^{2}$ Hongxia Qiao $\mathbb{D},{ }^{1,3}$ Theogene Hakuzweyezu $\mathbb{D}{ }^{1}$ \\ and $\mathrm{Kan} \mathrm{Li}^{1}$ \\ ${ }^{1}$ School of Civil Engineering, Lanzhou University of Technology, Lanzhou 730050, China \\ ${ }^{2}$ School of Science, Lanzhou University of Technology, Lanzhou 730050, China \\ ${ }^{3}$ Western Center of Disaster Mitigation in Civil Engineering of Ministry of Education, Lanzhou University of Technology, \\ Lanzhou 730050, China \\ Correspondence should be addressed to Hongxia Qiao; qhxlut7706@163.com
}

Received 19 August 2021; Revised 7 October 2021; Accepted 12 October 2021; Published 25 October 2021

Academic Editor: Yifei Hao

Copyright $(92021$ Chenggong Lu et al. This is an open access article distributed under the Creative Commons Attribution License, which permits unrestricted use, distribution, and reproduction in any medium, provided the original work is properly cited.

\begin{abstract}
Aiming at the prominent problem of short durability life of concrete in saline soil area and the shortcomings of indoor accelerated test, an outdoor field exposure test was designed. The concrete specimens were semiburied in the Tianshui area with salinized soil characteristics, and nondestructive testing was conducted every 180d (days). The durability evaluation parameters and mechanical performance indexes were selected for macroscopic analysis, and the corrosion mechanism was analyzed by using the SEM image and the XRD phase. The Birnbaum-Saunders model based on physical failure and probability statistics was used for life prediction. The results show that there are rod-shaped and chip-shaped crystals growing from the surface of the gel and the internal holes in the exposed end and the embedded end of the concrete. However, the damage and deterioration of the buried end are more serious than those of the exposed end. The corrosion products mainly included ettringite, gypsum, calcium carbonate, sodium sulfate hydrate, carbosilite, and Friedel's salt. The reliability life curve based on the Birnbaum-Saunders model can describe the whole process of exposed concrete from damage accumulation to failure. In addition, the dynamic modulus degradation index is more sensitive to concrete durability damage, and the life obtained by the Birnbaum-Saunders model is shorter than the quality degradation index. The life obtained by this degradation index is taken as the life of the concrete exposed in the saline soil site, and the concrete life of C30, C40, and C50 is about 3340d, 3930d, and 4360d, respectively.
\end{abstract}

\section{Introduction}

In the actual service environment, concrete is affected by various erosion factors, and its durability continues to decline. In the inland areas of northwestern China, where the largest saline soil is distributed [1], there are multiple environmental and climate damages such as corrosion, salt erosion [2], freeze-thaw damage [3], and dry-wet cycle [4], so that concrete structures in this area often fail to reach the specified service life and fail prematurely [5]. Exploring the law of concrete erosion and degradation in this area and predicting the service life of concrete are crucial for improving the reliability of concrete structures, strengthening the initial durability design, and carrying out postreinforcement maintenance [6,7]. However, due to the long period of outdoor durability tests and data collection difficulty, the current research on the corrosion degradation mechanism and erosion degradation analysis of concrete is mainly based on indoor tests. It mainly considers the main damage factors of structural concrete materials in a certain corrosive environment, designs the accelerated stress level on this basis to obtain the degradation process of structural concrete materials in a relatively short period $[8,9]$, and explores the damage mechanism $[10,11]$ to propose the ways and methods to improve the durability $[12,13]$. For example, Chen considered the electrochemical coupling effect and moisture convection effect on the transport of chlorine in unsaturated concrete. Under the verification of the moisture-multi-ion 
coupling transmission model, it was pointed out that, with the reduction of the dry-wet time ratio and the moisture boundary saturation during the drying process, the influence of the electrochemical coupling effect on the chloride ion transport greatly increased [14]. Aiming at the severe durability damage and deterioration of reinforced concrete caused by chloride salt erosion and alkali-silicon reaction, Mao proposed a special electrochemical method containing lithium compound anode solution, which would reduce chloride ion corrosion to reinforcement and the influence of alkalisilicon reaction on cracks [15]. Zhang mainly proposed a coupling model and reduction function for the impact of sulfate and chloride on reinforced concrete durability, as well as quantitatively analyzing the impact of sulfate erosion on chloride ion migration from the perspectives of solution concentration, soaking time, curing time, water binder ratio, and aggregate [16]. On the one hand, these findings provide a good reference and enlightenment for the durability design of reinforced concrete in harsh environments [12-16]. On the other hand, although the indoor accelerated test has many advantages in simulating concrete deterioration, such as a short test period, convenient testing, and few influencing factors, it still has a particular gap with the concrete degradation process in the actual service environment, and it cannot completely achieve the same degradation as the real service environment. Especially in the northwest saline soil area, it is not easy to realize indoor simulation due to a large number of damage and deterioration factors for concrete.

The outdoor exposure test can be as close to the concrete service environment as possible, and the data acquired on degradation can be used to predict durability life in a more realistic and guiding way.

Besides, in terms of concrete durability quantification and life prediction, researchers are mainly based on the mathematical model established by Fick's second law $[17,18]$ and continue to refine on this basis, so that the accuracy of life prediction is continuously improved. For example, based on statistical analysis and a large number of test results, Liu suggested a prediction model based on Fick's second law. The depth of chloride ion penetration and the chloride ion content at different depths were well predicted [19]. Other researchers also start from artificial intelligence using neural networks for intelligent learning and then realize life prediction [20]. Liu also made effective use of the characteristics of artificial neural network technology, established a network model through an extensive and reliable database composed of 653 diffusion coefficient results, and combined the 13 most influential parameters such as concrete composition, mechanical properties, and test procedures. The diffusion coefficient of chloride ions in concrete was predicted, and it was pointed out that an artificial neural network is an effective tool to identify the difference of experimental results and is suitable for evaluating the chloride ion corrosion resistance of reinforced concrete structures in complex and harsh environments [21]. Apart from the above-mentioned life prediction methods, based on the principle of probability and statistics, the life prediction methods based on reliability theory have gradually begun to be applied to the durability of concrete, using the Weibull function and Wiener function to realize and predict the life of concrete in a corrosive environment [22,23]. However, there is no relevant report on the application of the Birnbaum-Saunders (abbreviated as B-S) distribution model for predicting concrete durability life. The distribution model is derived from material fatigue damage and is a distribution model that satisfies the dual properties of physical failure and probability and statistics [24]. At the same time, unlike Fick's second law, which can only predict diffusion depth of ion, the distribution model can directly use a variety of degradation data indicating concrete's macro durability to realize life prediction. And unlike the Weibull distribution model, which requires a large number of data samples for parameter estimation, B-S distribution can use a small number of data samples to obtain more accurate parameter estimates. Based on this, the concrete was exposed in the saline soil area, carried out outdoor durability tests, selected the B-S distribution model for modeling, and predict the durability life of concrete in the northwest saline soil area.

\section{Experimental Procedure and Scheme Design}

2.1. Experimental Methods. Aiming at the current durability test of structural concrete materials, researchers mostly carry out indoor accelerated tests based on corrosion factors to simulate the one-sided and deficiencies caused by the damage and deterioration of concrete in the actual service environment. This paper proposes an outdoor field exposure concrete durability test program. The concrete specimens were placed in the saline soil environment in the northwest of China and then subjected to the combined effects of climate and environment; the degradation data were collected after a certain period of exposure. At the end of the test, damage tests were carried out, and microscopic investigation was carried out to analyze the degradation law and corrosion mechanisms of concrete in the actual service environment from both the macroscopic and microscopic aspects. In addition, most of the buildings in the actual service environment have both aboveground structures and underground structures, and the damage degree of different parts of the concrete was found to be different through field investigation. Hence, this experiment adopted a semiburied method for field exposure. Combined with the difficulty of outdoor data collection, the Tianshui area with the characteristics of saline soil and convenient transportation for exposure was selected. The soil quality analysis report of the exposed point is shown in Table 1. During the exposure period, the changing pattern of temperature, humidity, evaporation, and precipitation at the exposure point is shown in Figure 1. It can be seen from the figure that the temperature and humidity at the exposure point fluctuate throughout the four seasons of a year. The relative humidity during the exposure period is relatively large, the highest can reach $80 \%$, and the lowest is not less than $40 \%$. When the temperature is at its highest, both precipitation and evaporation are at their peak, with evaporation greatly outnumbering precipitation. At the same time, for most of the year, evaporation is higher than precipitation, providing an effective medium and power for the corrosion ions in the saline soil to enter the concrete. 
TABLE 1: Soil quality analysis report of saline soil.

\begin{tabular}{lccccrr}
\hline Ionic species & $\mathrm{CO}_{3}{ }^{2-}$ & $\mathrm{HCO}_{3}^{-}$ & $\mathrm{SO}_{4}{ }^{2-}$ & $\mathrm{Cl}^{-}$ & $\mathrm{Ca}^{2+}$ & $\mathrm{Mg}^{2+}$ \\
\hline Test results $(\mathrm{mg} / \mathrm{kg}$ soil) & 68 & 828 & 146 & 60 & 85 & 15 \\
\hline
\end{tabular}

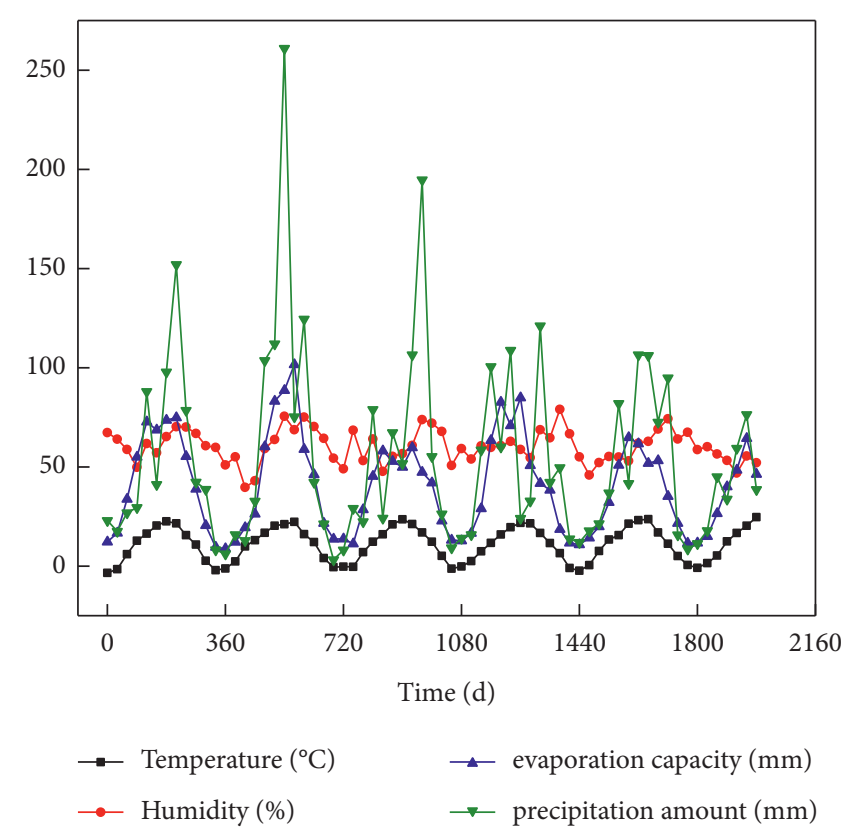

Figure 1: The climatic pattern of exposure points during the exposure period.

After tracing the relevant data reflecting the degradation of concrete durability performance, the $\mathrm{B}-\mathrm{S}$ distribution with a good description of the degradation data was selected for modeling, and the concrete reliability model under different exposure periods was obtained. Furthermore, the life of concrete in the service environment of saline soil was predicted, and quantitative standards for studying the acceleration coefficient, durability design, and actual engineering construction of indoor accelerated tests in the northwest saline soil area were provided.

2.2. Materials and Mixtures. This paper used C30, C40, and C50 strength grade concrete that have been refined by the research group for a long period to fully understand the durability degradation law and service life of different types of concrete in the field exposure environment. The number of concrete materials and some physical properties of each strength grade is shown in Table 2. Among them, the cement was made of P.O 42.5 cement produced by Gansu Qilianshan Cement Company, with a specific surface area $\geq 362 \mathrm{~m}^{2} / \mathrm{kg}$. The fly ash used was Lanzhou No. 2 Thermal Plant's fly ash II, which has a fineness of $6 \%$, a water demand ratio of $102 \%$, and a loss on ignition of $5.4 \%$. The relevant properties of the cementitious materials used are shown in Table 3. The coarse aggregate was the crushed stone provided by Lanzhou Hualong Commercial Concrete Company, with an apparent density of $2660 \mathrm{~kg} / \mathrm{m}^{3}$ and mud content of 0.5 . And the fine aggregate was natural river sand from Anning District of Lanzhou, with a fineness modulus of 3.18, an apparent density of $2581 \mathrm{~kg} / \mathrm{m}^{3}$, and mud content of $2.8 \%$.
The water-reducing agent was Lanzhou Hualong Commercial Concrete Company's hydroxy-based water-reducing agent, which had an $18 \%$ water reduction rate. The mixing water came from the tap water of the local municipal company, which meets the requirements of the "Concrete Mixing Water Standard" (JGJ63-2006).

2.3. Evaluation Index of Concrete Durability. The size of the specimen was $100 \times 100 \times 400 \mathrm{~mm}$ prism, and three test blocks of each strength level were used as a group. After $28 \mathrm{~d}$ of standard curing, it was transported to the exposed point for embedment, of which $200 \mathrm{~mm}$ was buried in saline soil, recorded as end $\mathrm{N} ; 200 \mathrm{~mm}$ was exposed to the atmosphere, recorded as end $M$, as shown in Figure 2. The YP20001 electronic balance and HC-U83 multifunctional concrete ultrasonic detector were used to test the mass and ultrasonic velocity of the specimen, respectively. The final durability evaluation value was the average of the three test samples, and the test period was $180 \mathrm{~d}$. And the ultrasonic sound velocity values were tested in three positions: the exposed end $\mathrm{N}$, the embedded end $M$, and the longitudinal $L$ end. At the end of the test, the specimen was brought back to the laboratory for mechanical properties and microscopic tests including SEM and XRD. SEM scanning was performed with a JSM-6701F cold field emission electron microscope with a resolution of $1.0 \mathrm{~nm}(15 \mathrm{KV})$ and XRD with a D8ADVANCE $\mathrm{X}$-ray diffractometer. The scanning range was $10^{\circ}-90^{\circ}(2 \theta)$ and the scanning speed was $2^{\circ} / \mathrm{min}$. The relative dynamic elastic modulus evaluation parameters and relative mass evaluation parameters that are normalized to the test results 
TABLe 2: Concrete mix ratio and physical properties $\left(\mathrm{Kg} / \mathrm{m}^{3}\right)$.

\begin{tabular}{lcccccccc}
\hline Cement & Fly ash & Coarse aggregate & Fine aggregate & Water & Water reducer & Compressive strength $(\mathrm{MPa})$ & Slump $(\mathrm{mm})$ & Strength grade \\
\hline 300 & 100 & 1155 & 664 & 170 & 6 & 32.2 & 170 & C30 \\
360 & 90 & 1167 & 634 & 158 & 9 & 41.1 & 170 & C40 \\
425 & 75 & 1173 & 647 & 150 & 13 & 54.3 & 175 & C50 \\
\hline
\end{tabular}

TABle 3: Chemical compositions of cement and fly ash (\%).

\begin{tabular}{lccccccc}
\hline Raw material & Loss on ignition & $\mathrm{SiO}_{2}$ & $\mathrm{Al}_{2} \mathrm{O}_{3}$ & $\mathrm{Fe}_{2} \mathrm{O}_{3}$ & $\mathrm{CaO}$ & $\mathrm{MgO}$ & $\mathrm{SO}_{3}$ \\
\hline Cement & 1.62 & 27.4 & 9.60 & 5.0 & 48.3 & 2.0 & 2.0 \\
Fly ash & 5.4 & 44.36 & 25.13 & 12.64 & 11.94 & 0.82 & 1.23 \\
\hline
\end{tabular}

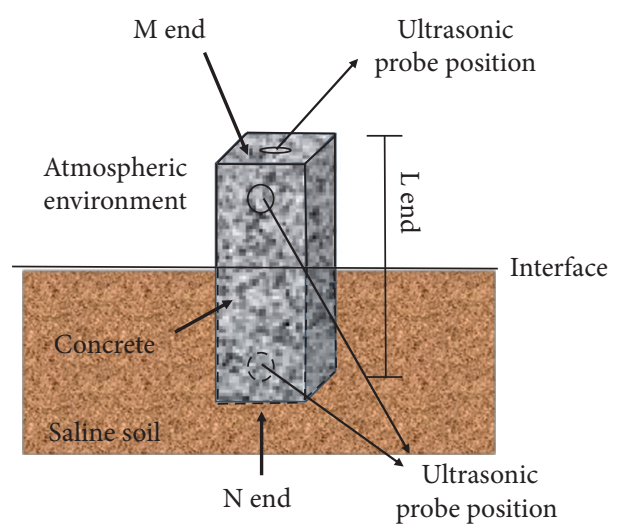

FIGURE 2: Schematic diagram of semiburied concrete.

were used to avoid measurement errors and other factors, as follows:

$$
\begin{aligned}
& \xi_{a}=\frac{V_{t}^{2} / V_{0}^{2}-0.6}{0.4}, \\
& \xi_{b}=\frac{W_{t} / W_{0}-0.95}{0.05},
\end{aligned}
$$

In the formula, $V_{t}$ and $W_{t}$ refer to the mean ultrasonic velocity and mass of the three specimens after a certain exposure period, and $V_{0}$ and $W_{0}$ refer to the mean ultrasonic velocity and mass of the specimens at the initial time. When $\xi$ is less than 0 , the concrete specimen is considered as failure destruction, and when $\xi$ is between 0 and 1 , the concrete specimen is considered as damage degradation.

\section{Analysis of Durability Test Results}

3.1. Analysis of Macroevaluation Results. The ultrasonic sound velocity and mass value of concrete collected under different exposure periods were brought into equations (1) and (2). The durability evaluation parameters of concrete with different strengths are shown in Figure 3, where $\xi_{a-M}$ represents the evaluation parameter of dynamic elastic modulus at the exposed end, $\xi_{a-N}$ represents the evaluation parameter of dynamic elastic modulus at the embedded end, and $\xi_{a-L}$ represents the evaluation parameter of longitudinal dynamic elastic modulus. It can be seen that, under the combined effect of climate and corrosive environment, the three types of concrete specimens all fluctuated with the increase of exposure time. The initial evaluation parameter value fluctuated compared to the time when the erosion has not started. This means that the corrosive ions such as $\mathrm{Cl}^{-}$, $\mathrm{SO}_{4}{ }^{2-}, \mathrm{CO}_{3}{ }^{2-}, \mathrm{HCO}_{3}{ }^{-}$in the saline soil were continuously migrated into the concrete through the concrete surface pores under the action of capillary adsorption. With gel hydration products, it generates ettringite, gypsum, calcium carbonate, Friedel's salt, and other expanded crystals to fill the pores, cavities, and defects in the concrete. The internal pore structure is improved to a certain extent, the density of concrete has increased, the propagation speed of ultrasonic waves in concrete has increased, and the macroscopic performance increases the value of $\xi_{a}$. Simultaneously, the freeze-thaw damage and dry-wet cycle caused by the initial climate change have not yet destroyed the concrete, so the surface of the specimen was relatively complete, and there is no quality loss behavior such as peeling and slagging. At this time, the corrosive ions in the saline soil enter the concrete to solidify, and the formation of corrosive expansion crystals is the main cause of the increase in quality. With the increase of outdoor exposure time, more corrosive ions were cured in concrete, and more hydration products of cementing materials were consumed, particularly calcium silicate hydrate $(\mathrm{C}-\mathrm{S}-\mathrm{H})$ and calcium aluminate hydrate $(\mathrm{C}-\mathrm{A}-\mathrm{H})$, which mainly have the cementing property, and calcium hydroxide $(\mathrm{CH})$, which keeps the alkalinity inside the concrete.

When the number of internal gels in concrete, cementation between aggregates, and $\mathrm{pH}$ value decrease, 


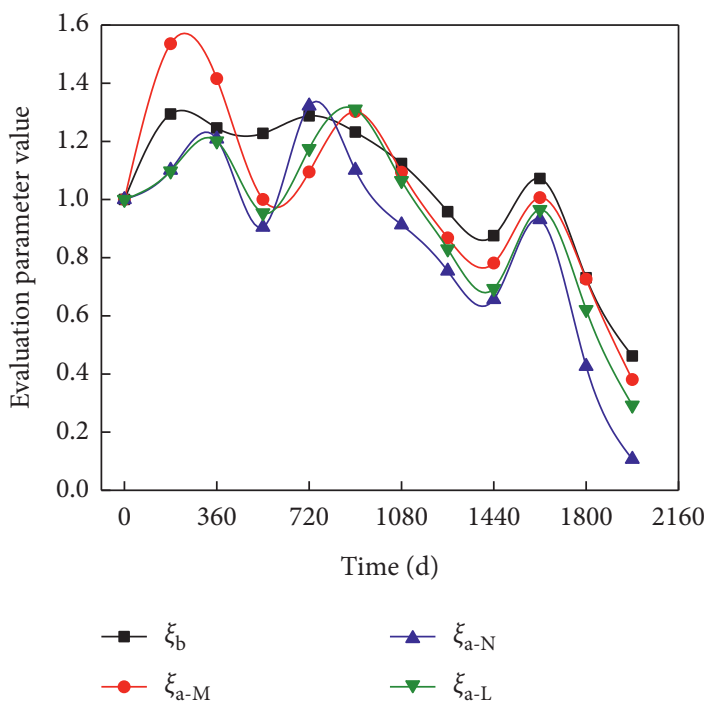

(a)

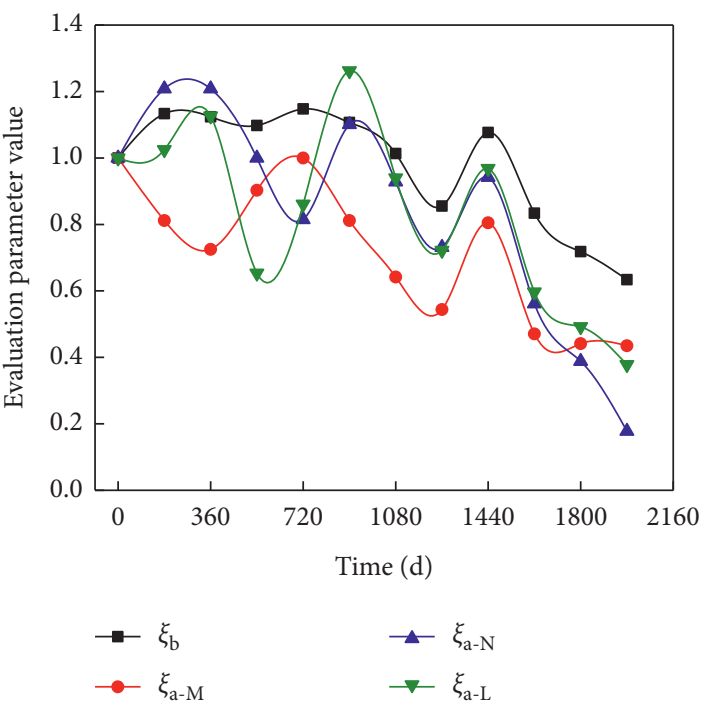

(b)

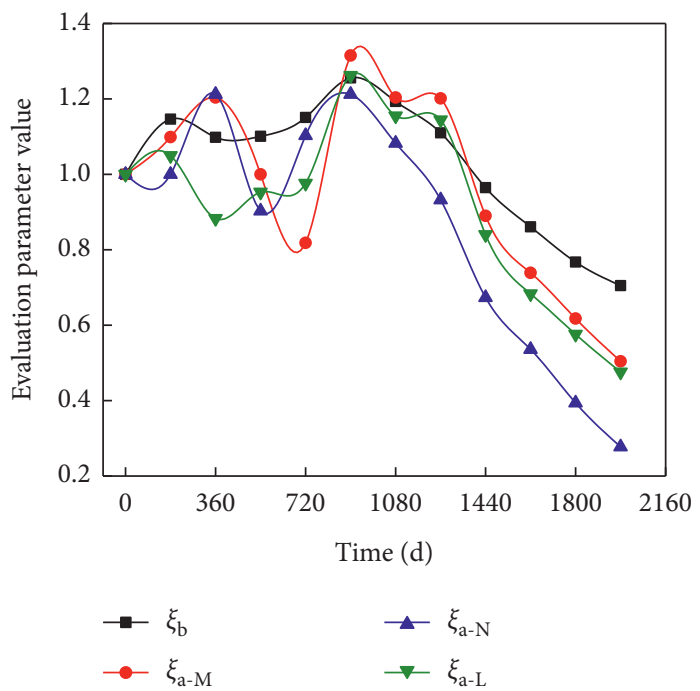

(c)

Figure 3: Durability evaluation parameters of concrete with different strength grades. (a) C30 Concrete. (b) C40 Concrete. (c) C50 Concrete.

decalcification occurs. In addition, the more corroded crystals are formed, the more expansion stress is generated, causing tensile stress on the surrounding pore wall. When the expansion stress is large enough, the inner pore wall is cracked. At this time, the dry-wet cycles and freeze-thaw cycles caused by climate change also damage the concrete. On the one hand, the dry-wet cycles' power promotes the continuous migration of corrosive ions deeper inside the concrete. Meanwhile, the corrosive salt is more likely to crystallize out, producing an intense salt crystallization stress on the surface concrete, and crisscross microcracks gradually appear on the surface concrete. On the other hand, the freeze-thaw damage caused by the seasons' alternation also gradually takes effect, causing the concrete to produce temperature stress and expansion stress. This type of damage continues to accumulate and causes the concrete hole wall to crack. The combined effect of the various factors mentioned above together produces corrosion damage to the concrete. The longer the outdoor exposure time, the more the solidification of corrosive ions, and the more the gel consumed. The number and width of cracks produced by the penetration of the inner wall of the concrete hole are also increased and deepened.

When the exposure period exceeds $1080 \mathrm{~d}$, the specimen's mass loss due to peeling, desquamation, and corner breakage gradually exceeds the expanded crystal formed by the solidification of corrosive ions. There are microcracks on the surface and inside of the specimen, the gel is consumed, and the density decreases. The macroscopic performance indicates that the relative quality and the relative dynamic elastic modulus evaluation parameter values continue to decline. The lower the concrete strength grade, the smaller 
the evaluation parameter value in the later period of exposure, and the more serious the deterioration. Also, the lower the strength grade, the greater the fluctuation range of the evaluation parameter value during the entire exposure period, resulting in unstable durability performance. Comparing the different evaluation parameters of each strength grade's concrete, it can be observed that the relative quality evaluation parameters fluctuate relatively smoothly. At the end of the exposure, the $\xi_{b}$ value is higher than the $\xi_{a}$ value, indicating that the dynamic elastic modulus of concrete under saline soil's outdoor exposure conditions is more sensitive to environmental changes. And from the dynamic elastic modulus' evaluation parameters measured in different directions, the value of $\xi_{a}$ at the embedded end (end $\mathrm{N}$ ) in the later stage of exposure is smaller than that of the exposed end (end M). When the $\xi_{a}$ value in the longitudinal direction ( $\mathrm{L}$ end) is between the buried end and the exposed end, the deterioration of the buried end concrete in the saline soil exposed environment is more serious. The main reason is that the concrete at the embedded end is in direct contact with the saline soil with large amount of corrosion ions, resulting in a high crystallization stress and expanded crystals. On the contrary, when the exposed end is not in direct contact with the saline soil, the power of corrosion ions in the exposed end concrete mainly comes from the "wick effect" [25], the number of corrosion ions is not as large as that of the buried end, and the corrosion effect of corrosion salt is weaker than that of the buried end. However, the longitudinal ultrasonic inspection passes through the exposed end and the embedded end simultaneously, so the value of $\xi_{a}$ is between the two, and the overall corrosion damage of the concrete is also between the two types of erosion. Therefore, it can be considered that the evaluation parameters of longitudinal dynamic elastic modulus are more comprehensive and reasonable in evaluating the durability of semiburied saline soil concrete.

After the on-site exposure, the specimens were transported back to the laboratory for flexural and compressive strength testing. The strength values of concrete specimens with different grade and different parts are shown in Figure 4. It can be observed from Figure 4(a) that, under the combined effects of climate and environment in the saline soil area, the flexural strength of concrete after $1980 \mathrm{~d}$ on-site exposure has changed significantly, all of which are lower than the initial value. The rate of flexural strength loss of C30, C40, and C50 concrete reached $30.2 \%, 20.4 \%$, and $19.3 \%$, respectively, indicating that the concrete has suffered greater damage. The lower the strength level, the greater the loss and deterioration. It can be observed that the compressive strengths of the exposed end and the embedded end of the three types of strength concrete specimens are lower than the initial value, but the reduction of the embedded end is greater. Among them, the C30 concrete embedded end and the exposed end are reduced by about $21.9 \%$ and $15.9 \%$, respectively, from the initial compressive strength. In comparison, the C50 concrete is $11.1 \%$ and $7.4 \%$, and the C40 concrete is between the two, $14.6 \%$ and $9.8 \%$. This shows that the deterioration of the buried end in saline soil's exposed environment is more severe, which is consistent with the conclusion obtained through the nondestructive evaluation parameters.

3.2. Microresult Analysis. To better explore the damage and deterioration of concrete in the service environment of saline soil, the most severely damaged C30 was used for conducting microscopic tests after the mechanical performance test of the exposed concrete on-site. The SEM images and XRD phase analysis of different positions are shown in Figures 5 and 6, where the magnification of Figure 5 is 10000 times. It can be observed from the SEM image that there are rod-shaped and needle-shaped crystals growing from the surface of the gel and holes in the concrete at the exposed end and the embedded end. Among them, the amount of exposed end crystals is small but stronger, while the amount of embedded end crystals is large, small, and dense, and they are distributed in a crisscross pattern.

These crystals are formed by complex physical and chemical reactions between corrosive ions, and cement hydration products, which consume the gel and maintain the alkaline $\mathrm{Ca}(\mathrm{OH})_{2}$ inside the concrete, and generate strong expansion stress. Under the combined action of the dry-wet and freeze-thaw cycles, the concrete's internal pore walls are pulled and cracked, and then microcracks are formed. The concrete's density continues to decrease, the amount of cement decreases, and the deterioration gradually increases. Combined with the XRD phase analysis, it can be seen that the buried end that is in direct contact with the saline soil has not only ettringite $\left(3 \mathrm{CaO} \cdot \mathrm{Al}_{2} \mathrm{O}_{3} \cdot \mathrm{CaSO}_{4} \cdot 32 \mathrm{H}_{2} \mathrm{O}\right)$, gypsum $\left(\mathrm{CaSO}_{4} \cdot 2 \mathrm{H}_{2} \mathrm{O}\right)$, calcium carbonate, Friedel's salt $\left(3 \mathrm{CaO} \cdot \mathrm{Al}_{2} \mathrm{O}_{3} \cdot \mathrm{CaCl}_{2} \cdot 10 \mathrm{H}_{2} \mathrm{O}\right)$, sodium sulfate hydrate, and other swelling crystals are formed, but also thaumasite $\left(\mathrm{Ca}_{3} \mathrm{SiSO}_{4} \mathrm{CO}_{3}(\mathrm{OH})_{6} \cdot 12 \mathrm{H}_{2} \mathrm{O}\right)$, as well as wollastonite gypsum. At the same time, there is also the formation of nongelling magnesium hydroxide, indicating that more corrosive ions in the saline soil enter the concrete, and complex reactions occur, which cause greater damage to the durability of the concrete. However, from the XRD phase analysis of the exposed end, it was found that no mothonite, Friedel's salt, and magnesium hydroxide were generated in the exposed end concrete, indicating that the corrosion degradation of the exposed end concrete is weaker than that of the buried end. This is related to the number and types of corrosion ions that enter the concrete at the exposed end through capillary adsorption and the "wick effect." However, ettringite, gypsum, calcium carbonate, sodium sulfate hydrate, and other swelling crystals are still formed, which will cause greater damage to the concrete's internal pores and gels. The longer the exposure period, the more serious the damage and deterioration of the concrete.

\section{The B-S Life Prediction Model}

4.1. The B-S Model Theory and Parameter Estimation. In the on-site exposure environment of saline soil, the deterioration of concrete results from the comprehensive effects of many damage factors, such as corrosive ions, dry and wet, 


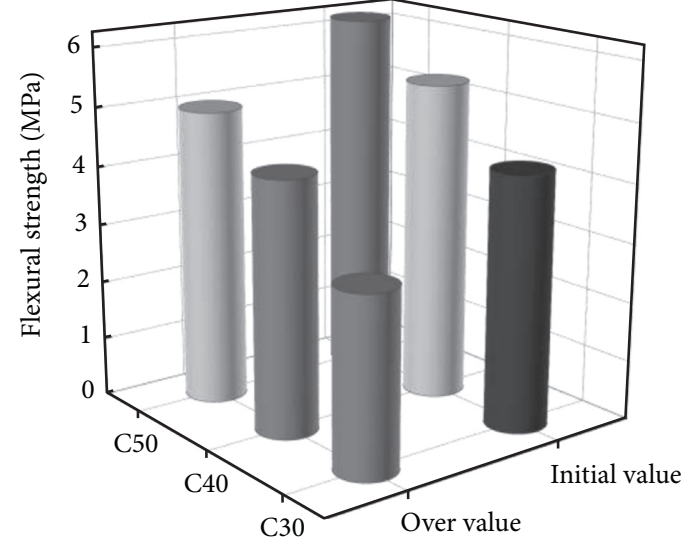

(a)

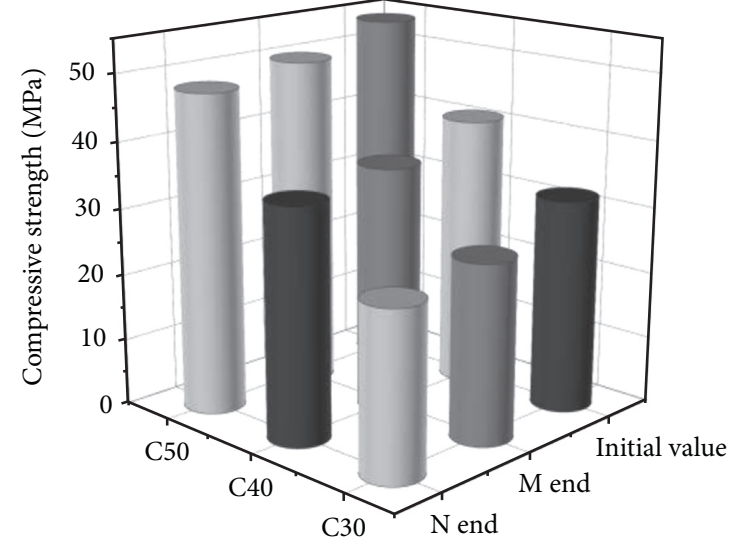

(b)

FIgURE 4: Change of mechanical properties of concrete. (a) Flexural strength value. (b) Compressive strength value.

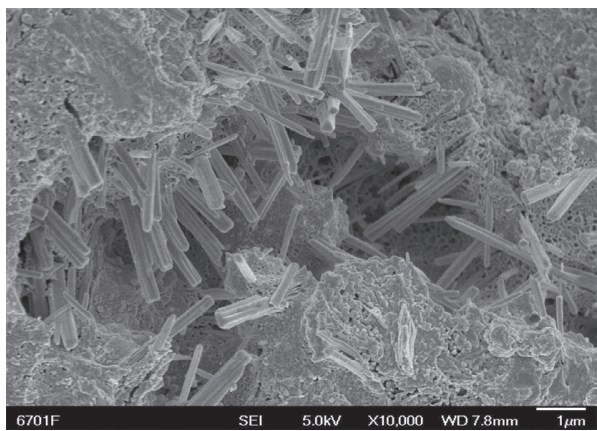

(a)

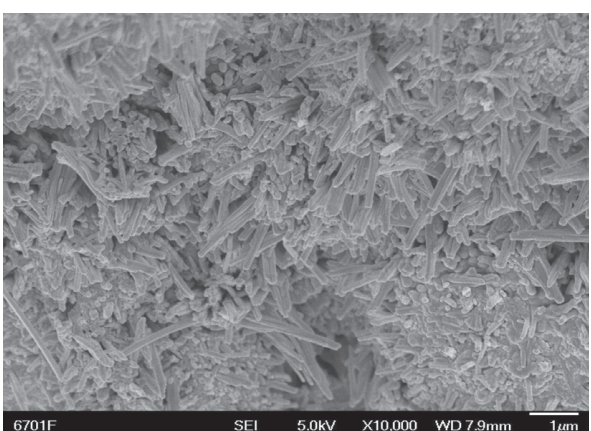

(b)

Figure 5: SEM diagram of different positions of concrete. (a) The exposed end. (b) The embedded end.
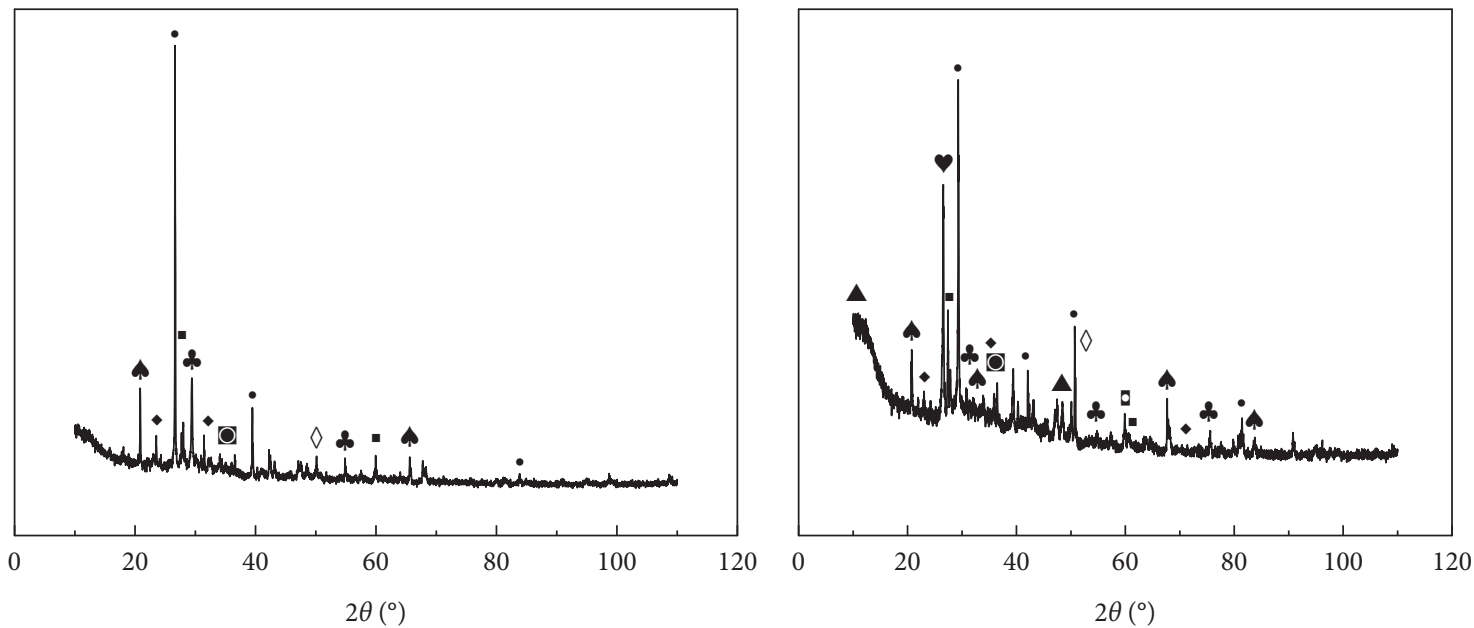
- $\mathrm{SiO}_{2}$
- Ettringite
+f $\mathrm{CaCO}_{3}$
o Portlandite

- Sodium sulfate hydrate

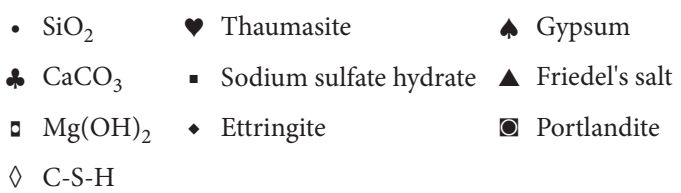

(b)

FiguRE 6: XRD of different positions of concrete. (a) The exposed end. (b) The embedded end. 
freeze-thaw, solar radiation. With the increase of exposure time, this deterioration has periodicity and reciprocation. When the cumulative damage reaches the concrete failure threshold, the concrete is damaged. The B-S life distribution model is a type of life model derived based on material fatigue, which reflects the physical failure process of materials and has the characteristics of probability and statistics. Hence, it is suitable for product life analysis under periodical damage. Based on this, this paper also uses the $\mathrm{B}=\mathrm{S}$ model to analyze and predict the durability of concrete in the environment of saline soil exposure. Assuming that, under the exposure environment, the loss of the $k$-th durability degradation index at the end of the $j$-th exposure period of concrete is $\Delta X_{j k}$, where $k=1$ is the quality degradation index, and $k=2$ is the dynamic elastic modulus degradation index, after the end of the $n$ exposure period, the durability degradation amount is [26]

$$
W_{n k}=\sum_{j=1}^{n} \Delta X_{j k}
$$

Simultaneously, assuming that $\Delta X_{j k}$ is an independent and identically distributed random parameter, the mean value is $\mu$, and the variance is $\sigma^{2}$. When the durability degradation $W_{n k}$ exceeds the critical threshold $\varpi_{k}$ for the first time, the concrete is considered invalid. The failure probability can be expressed as [26]

$$
P\left(W_{n k} \geq \varpi_{k}\right)=1-P\left(\sum_{j=1}^{n} \Delta X_{j k} \geq \varpi_{k}\right) .
$$

When $n$ is large enough, combined with the central limit law and the symmetry of the normal distribution, there is [27]

$$
P\left(W_{n k} \geq \varpi_{k}\right)=1-\Phi\left(\frac{\varpi_{k}-n \mu}{\sqrt{n} \sigma}\right)=\Phi\left(\frac{n \mu}{\sigma \sqrt{n}}-\frac{\varpi_{k}}{\sigma \sqrt{n}}\right) .
$$

In the formula, $\Phi(\cdot)$ is the standard normal distribution function. Because concrete is a long-life, high-reliability product, it can experience more cycles of damage and degradation before failure and destruction, so a continuous time $t$ can be used to replace $n$ discrete times. At the same time, it combines the distribution function with the reliability function and density, and the relationship between the function and failure rate function is [28]

$$
\begin{aligned}
& R(t)=1-\Phi\left(\frac{1}{\alpha}\left(\sqrt{\frac{t}{\beta}}-\sqrt{\frac{\beta}{t}}\right)\right), \\
& f(t)=\frac{1}{2 \alpha \sqrt{\beta}}\left(\frac{1}{\sqrt{t}}+\frac{\beta}{t \sqrt{t}}\right) \Phi\left(\frac{1}{\alpha}\left(\sqrt{\frac{t}{\beta}}-\sqrt{\frac{\beta}{t}}\right)\right), \\
& h(t)=\frac{f(t)}{R(t)}
\end{aligned}
$$

In the formula, the shape parameter $\alpha=\sigma /(\mu \omega)^{0.5}$, the scale parameter $\beta=\omega / \mu, \mu$, and $\sigma$ can be estimated by the estimation method [29]:

$$
\begin{aligned}
& \mu=\sum_{j=1}^{n} \frac{\Delta X_{j k}}{n}, \\
& \sigma=\sqrt{\sum_{j=1}^{n} \frac{\left(\Delta X_{j k}-\mu\right)^{2}}{n} .}
\end{aligned}
$$

The failure threshold is the boundary value for judging whether the product is in a "normal" state. According to the relevant regulations in the "Test Methods for Long-term Performance and Durability of Ordinary Concrete," the relative mass loss rate of $5 \%$ and the relative dynamic elastic modulus loss rate of $40 \%$ are the failure thresholds of each durability degradation index of concrete, that is, $\Phi_{1}=0.05$ and $\varpi_{2}=0.4$. Replacing the durability degradation data and failure thresholds into formulas (9) (10), and the shape parameter and position parameter formulas, the estimated values of the parameters of different strength concrete can be obtained, as shown in Table 4.

4.2. Analysis of Life Prediction Results. Substituting the parameter estimation obtained in Table 4 into equations (6)-(8), the degree of reliability curves, density curves, and failure rate curves under different degradation indexes and different parts of concrete are shown in Figures 7-9, where $Q$ denotes the mass index, and $M$ refers to the relative dynamic elastic modulus index of the exposed end, $N$ refers to the relative dynamic elastic modulus index of the embedded end, and $L$ denotes the longitudinal relative dynamic elastic modulus index. It can be observed from the reliability life curve that the reliability life curve of each strength concrete shows a three-stage change; that is, the reliability of the first stage is maintained at 1.0, the reliability of the second stage is accelerated, and the reliability of the third stage is reduced to zero. The first stage is a period where the durability of concrete is maintained. Although various damage factors continue to erode the concrete, the performance of the concrete remains good. Therefore, this stage is mainly a process of accumulation of various damages and degradations caused by climate and environment in the saline soil area. The higher the concrete strength is, the more the time it takes for the quantitative change accumulation process.

From the quality degradation index, the duration of the first stage of C30, C40, and C50 concrete is about $3000 \mathrm{~d}$, $4520 \mathrm{~d}$, and $5800 \mathrm{~d}$, respectively. The duration of the first stage obtained by the relative dynamic elastic modulus degradation index is shorter, and there are also differences in the duration of the exposed end, the embedded end, and the longitudinal direction. Among them, the embedded end has the shortest quantitative change duration, the exposed end has the longest duration, and the longitudinal duration is somewhere between $2220 \mathrm{~d}, 2480 \mathrm{~d}$, and $3130 \mathrm{~d}$. This indicates that, in the field exposure environment of saline soil, the dynamic elastic modulus degradation index is more sensitive to durability, while the quality degradation index is relatively lagging. It also reflects that the embedded end's concrete damage degradation is more severe than that of the 
TABLE 4: Estimated parameters of B-S life model.

\begin{tabular}{|c|c|c|c|c|c|c|c|c|}
\hline \multirow{3}{*}{ Parameter } & \multirow{2}{*}{\multicolumn{2}{|c|}{ Mass index }} & \multicolumn{6}{|c|}{ Dynamic elastic modulus index } \\
\hline & & & \multicolumn{2}{|c|}{$M$ Position } & \multicolumn{2}{|c|}{$N$ position } & \multicolumn{2}{|c|}{$L$ Position } \\
\hline & $\alpha$ & $\beta$ & $\alpha$ & $\beta$ & $\alpha$ & $\beta$ & $\alpha$ & $\beta$ \\
\hline C30 & 0.06801 & 3679.28 & 0.09383 & 3198.19 & 0.08104 & 2216.90 & 0.07519 & 2799.33 \\
\hline$C 40$ & 0.05796 & 5405.22 & 0.06472 & 3505.17 & 0.06973 & 2408.63 & 0.09055 & 3183.06 \\
\hline C50 & 0.04681 & 6711.78 & 0.07985 & 3994.15 & 0.06165 & 2740.35 & 0.06025 & 3775.84 \\
\hline
\end{tabular}

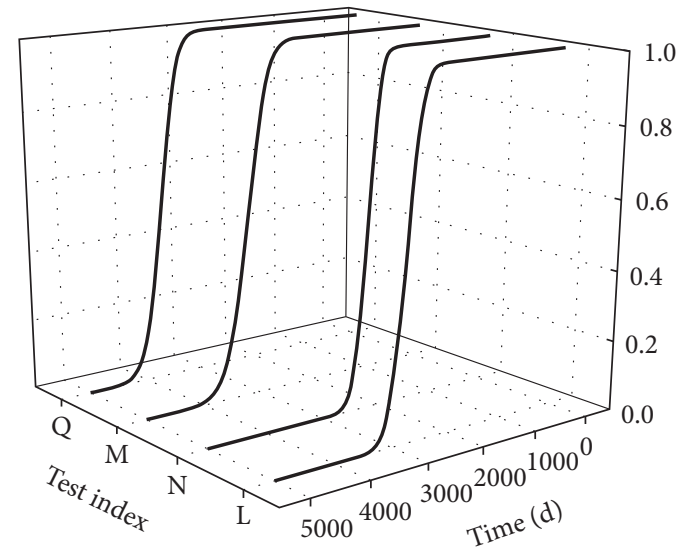

(a)

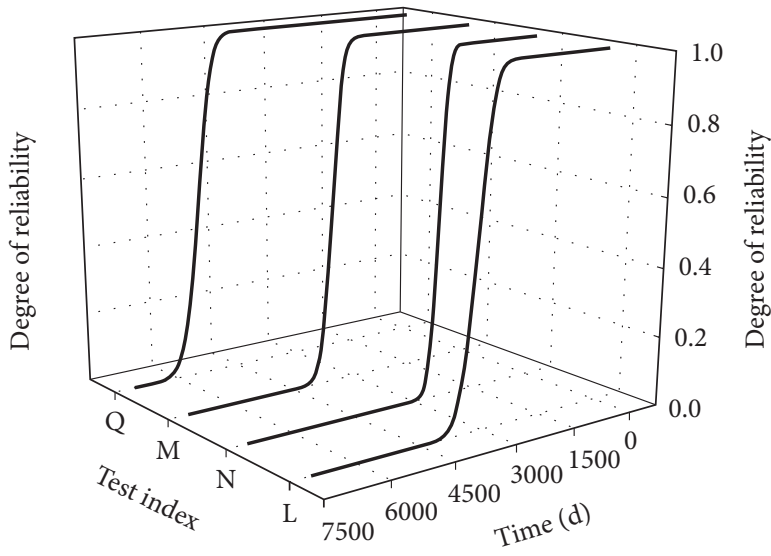

(b)

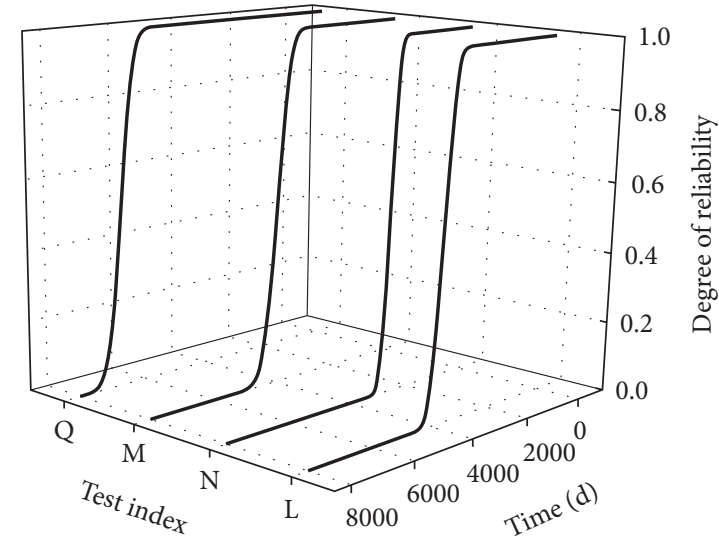

(c)

Figure 7: Life curve of different concrete. (a) C30 concrete. (b) C40 concrete. (c) C50 concrete.

exposed end, and the quantitative change accumulation lasts shorter. This is related to the direct contact between the concrete at the embedded end and the saline soil, and corrosion ions are more likely to enter the interior of the concrete.

As the exposure time increases, the damage and degradation gradually accumulate, and when the amount of damage and deterioration accumulates to a certain extent, qualitative changes occur, and the durability of concrete is significantly damaged, and then the reliability begins to decrease with the increase of exposure time gradually. The higher the concrete strength level, the stronger the resistance to corrosion and deterioration, and the longer the second stage's duration. When the reliability drops to zero, the concrete fails and breaks during the third stage. Therefore, the end time of the second stage can be used as the durability life of concrete in saline soil's exposed environment. It can be seen from the figure that the durability life obtained by the quality degradation index is the longest; C30, C40, and C50 are $4610 \mathrm{~d}, 6190 \mathrm{~d}$, and $7490 \mathrm{~d}$, respectively, while the durability life obtained by the dynamic elastic modulus is shorter. The durability of the concrete's exposed end was 3970d, 4080d, and 4810d, while the durability of the buried end was $1680 \mathrm{~d}, 2830 \mathrm{~d}$, and $3170 \mathrm{~d}$. In the longitudinal degradation index test, the ultrasonic can penetrate the embedded end and the exposed end, and the evaluation of the exposed concrete's durability on-site is more reasonable. Simultaneously, considering that the quality degradation index's sensitivity is less than the dynamic elastic modulus, the life of longitudinal degradation index is selected as the durability life value of exposed concrete in saline soil area, which is $3340 \mathrm{~d}, 3930 \mathrm{~d}$, and $4360 \mathrm{~d}$, respectively. 


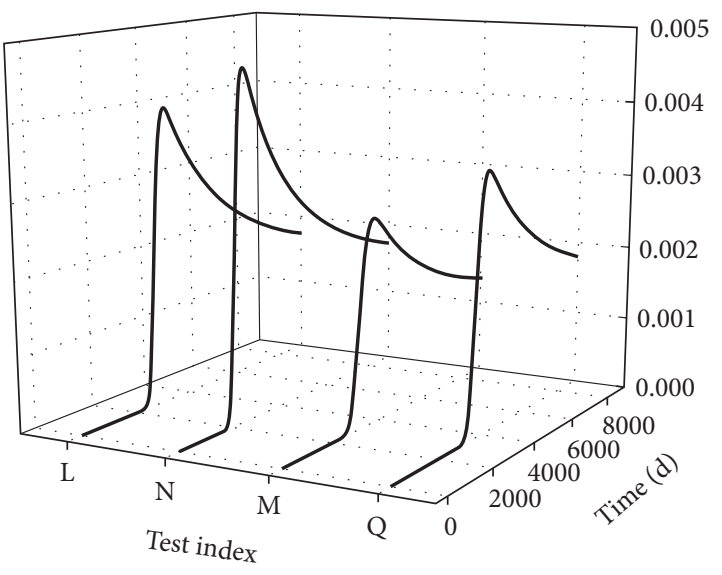

(a)

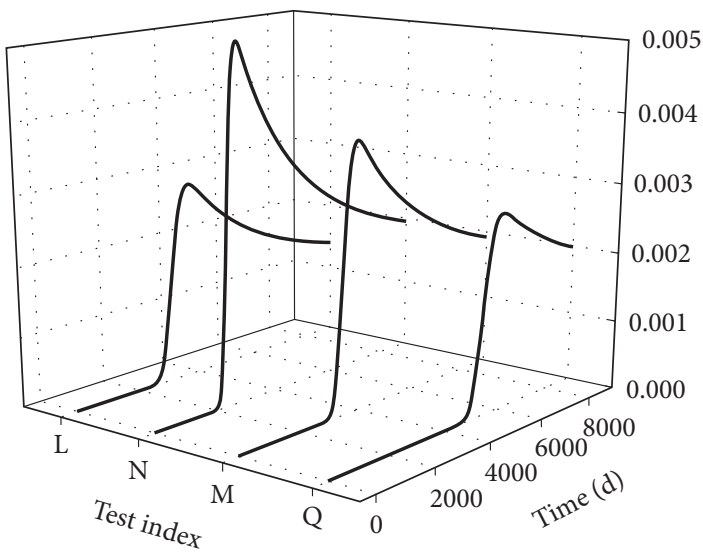

(b)

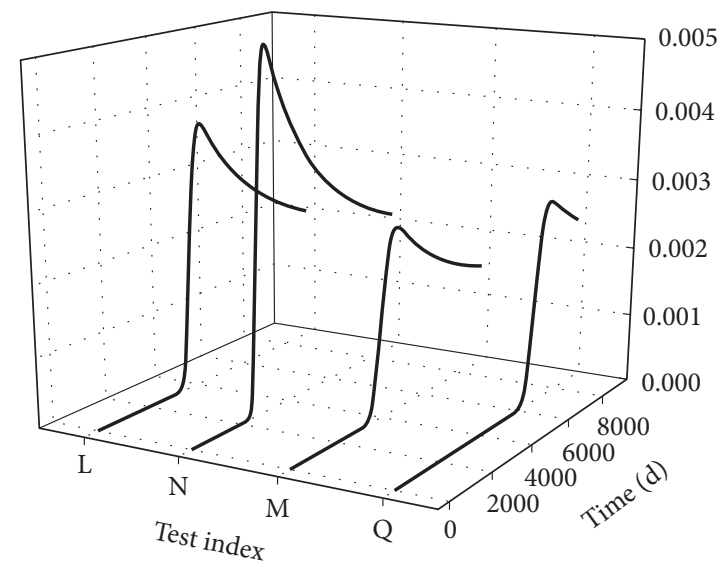

(c)

Figure 8: Density curve of different concrete. (a) C30 concrete. (b) C40 concrete. (c) C50 concrete.

Furthermore, density is the probability of concrete failure under the action of various damage factors per unit time. It can be seen from the density curve that the density curve is different from the single-peak symmetrical shape of the standard distribution density curve in the field exposure environment of saline soil, and it presents an "Inverted bathtub" form. At the initial stage of exposure, the density is zero, indicating that the probability of failure is extremely low. As the exposure time increases, damage and degradation gradually accumulate, the probability of failure increases, and the density curve rises until it reaches a peak. At this time, the probability of failure of concrete under the action of various damage factors is the greatest. Among the density curves of various strength concretes, the density curve of the quality degradation index has the longest duration to reach the peak point, followed by the duration of the exposed end and the shortest duration of the embedded end, which is consistent with the conclusion obtained from the reliability curve. In order to reflect the occurrence rate of concrete failure in the exposed environment of saline soil, the reliability and density are used to obtain the concrete failure rate at any time $t$. The failure rate curve in Figure 9 shows that the failure rate of concrete changes in two stages; that is, the failure rate is zero, and the acceleration rises in two stages. It can be seen from the changing trend of the failure rate curve that the deterioration of concrete in the onsite exposure environment of saline soil is a typical cumulative loss type failure. The initial failure rate is zero, resulting from the concrete material resisting external corrosion. As the damage degradation cycle increases, the damage gradually accumulates, and the concrete's ability to resist various damage factors begins to decline the failure rate increases. The longer the exposure period, the faster the failure rate until the concrete is destroyed. Among the three types of concrete, the lower the strength grade, the shorter the failure rate in the first stage. The first stage of the quality degradation index is the longest, and the failure rate is the smallest in the same exposure period. The first stage of the dynamic elastic modulus degradation index has a short duration. The embedding end has the shortest time, the longitudinal is slightly longer, and the exposed end is the longest, indicating that the damage of the exposed end is less degraded than the embedded end.

In short, under the site-exposed environment of saline soil, the concrete has experienced a variety of corrosive ions erosion and deterioration caused by dry-wet cycle and freeze-thaw cycle. The concrete with lower strength grade and the concrete buried in saline soil have a greater degree of 


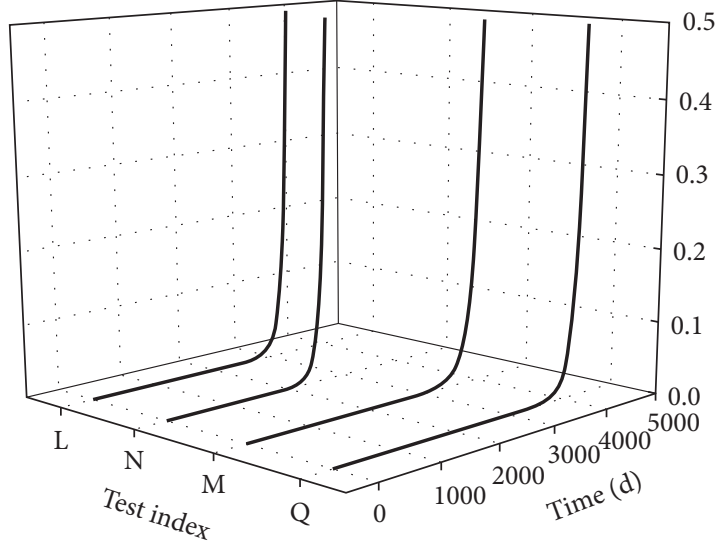

(a)

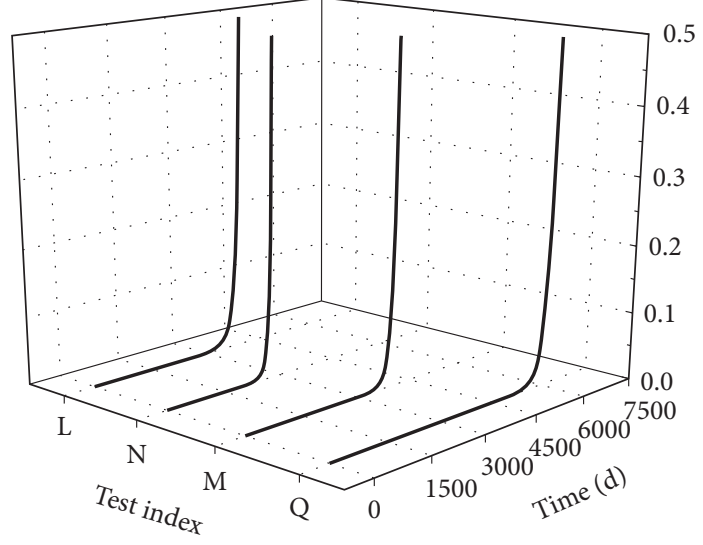

(b)

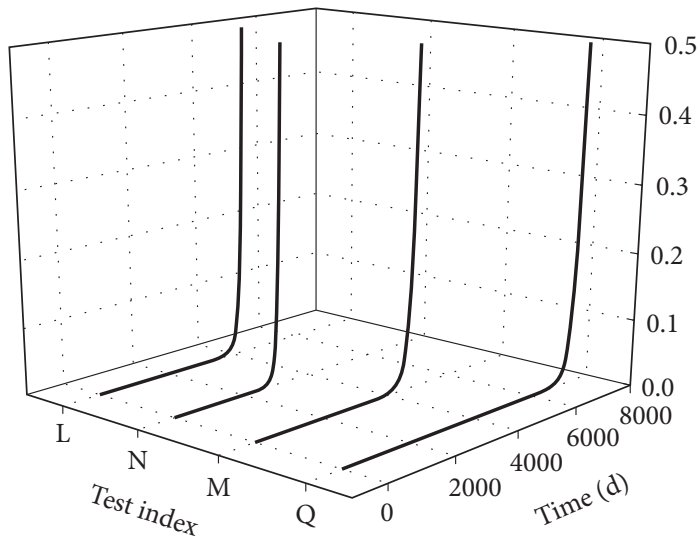

(c)

FIgURE 9: Failure curve of different concrete reliability. (a) C30 concrete. (b) C40 concrete. (c) C50 concrete.

deterioration, which is mainly because there are more corrosion ions in the concrete at embedded end. Moreover, the compactness of low strength concrete is small, and the corrosion ions are easier to enter the concrete through the pores. Therefore, for the concrete structure serving in the saline soil, improving the strength level of the concrete and adding protective materials on the surface of the concrete to prevent the erosion of corrosive product ions are important ways and methods to improve its durability.

\section{Conclusion}

The macro durability degradation law and micro erosion mechanism of three types of concrete semiburied in the Western saline soil area were studied and analyzed. Based on the B-S model, the service life was predicted by using the mass and dynamic elastic modulus degradation data obtained from the durability test. The following conclusions were drawn:

In the field exposure environment of saline soil, the degradation index of dynamic elastic modulus is more sensitive to the change of concrete durability damage, and the longitudinal dynamic elastic modulus also considers the damage of the embedded end and the exposed end. Taking the life of the longitudinal dynamic elastic modulus degradation index as the life of the exposed concrete in the saline soil, the C30, C40, and C50 concrete are approximately $3340 \mathrm{~d}, 3930 \mathrm{~d}$, and $4360 \mathrm{~d}$, respectively.

In the exposed end and the embedded end, rod-shaped and needle-shaped crystals grow from the surface of the gel and internal pores, and the number of crystals at the exposed end is small and thick. The corrosion products mainly include ettringite, Gypsum, calcium carbonate, and sodium sulfate hydrate. The embedded end crystals are dense and distributed in a crisscross pattern; corrosion products also include moissanite, Friedel's salt, and magnesium hydroxide. Based on the B-S life model of physical failure and probability statistics, the reliability life curve changes in three stages: the first stage is the process of quantitative change of each damage factor, the second stage is the quality change caused by the quantitative change, and during the third stage, the concrete failed and was destroyed, and the reliability dropped to zero.

Through the B-S life prediction model, it is obtained that the durability life of the exposed concrete is different under different degradation indicators. The life expectancy obtained from the quality degradation index is longer than the dynamic elastic modulus degradation index. The life span is 
the shortest, and the exposed end concrete has the longest life span. The life span of the concrete obtained in the longitudinal test is between the buried end and the exposed end life.

\section{Data Availability}

Some models or codes that support the findings of this study are available from the corresponding author upon reasonable request.

\section{Conflicts of Interest}

The authors declare that they have no conflicts of interest.

\section{Authors' Contributions}

All authors approved the manuscript for publication.

\section{Acknowledgments}

The authors acknowledge the financial support from the National Natural Science Foundation of China (nos. 51168031 and 51868044).

\section{References}

[1] Y. zheng, R. Xiuling, Z. Wen, L. Luo, and W. Kai, "The research development and thinking about the expansibility property of saline soil in northwest region," Chinese J Soil Sci, vol. 47, no. 1, pp. 246-252, 2016.

[2] S. Zhigang, X. Li, X. Shihua, and Q. Yangyan, "Corroded product surface layer of concrete corroded by sulfuric acid and its effect on corrosion rate," Journal of Building Materials, vol. 32, no. 20, pp. 3546-3552, 2018.

[3] X. Guan, Q. Jisheng, and P. Du, "Research on the evaluation method of damage degree of coal gangue concrete under freezing-thawing," Materials Review, vol. 32, no. 20, pp. 3546-3552, 2018.

[4] J. Gong, J. Cao, and Y.-f. Wang, "Effects of sulfate attack and dry-wet circulation on creep of fly-ash slag concrete," Construction and Building Materials, vol. 125, pp. 12-20, 2016.

[5] C. Wang, G. Ge, and J. Hou, "Study of durability of concrete structures and its influencing factors in south region of Xinjiang," J Wuhan Univ (Engineering Ed, vol. 50, no. 3, pp. 447-453, 2017.

[6] J. Zhang, P. Li, Z. Dong, and Y. Mao, "Study on some reliability evaluation problems of existing highway bridges," China Civil Engineering Journal, vol. 219, no. s1, pp. 159-173, 2019.

[7] T. A. Van-Loc, T. Senga Kiesse, S. Bonnet, and A. Ventura, "Application of sensitivity analysis in the life cycle design for the durability of reinforced concrete structures in the case of XC4 exposure class," Cement and Concrete Composites, vol. 87, pp. 53-62, 2018.

[8] S. A. Ghahari, A. M. Ramezanianpour, A. A. Ramezanianpour, and M. Esmaeili, "An accelerated test method of simultaneous carbonation and chloride ion ingress: durability of silica fume concrete in severe environments," Advances in Materials Science and Engineering, vol. 2016, no. 1, 12 pages, Article ID 1650979, 2016.

[9] X. P. Su and T. T. Wang, "Experimental study on the concrete performance corroded by different salts under the condition of freezing-thawing cycles," Applied Mechanics and Materials, vol. 744-746, pp. 118-121, 2015.

[10] Q. Huang, C. Wang, C. Yang, Y. Zhou, and C. Zhang, "Deterioration and its mechanism of concrete under combined action of electrical field and sulfate attack," Ournal Chinese Ceram Soc, vol. 44, no. 2, pp. 239-245, 2016.

[11] G. Zhao, J. Li, M. Shi, J. Cui, and F. Xie, "Degradation of castin-situ concrete subjected to sulphate-chloride combined attack," Construction and Building Materials, vol. 241, Article ID 117995, 2020.

[12] J. Zeng, S. Wang, Z. Fan, and J. Xiong, "Improvement effect and mechanism of metakaolin on marine concrete chloride penetration resistance," Journal of Wuhan University of Technology, vol. 37, no. 4, pp. 22-28, 2015.

[13] C. Wang, Z. Guo, and D. Niu, "Influence of the fiber volume content on the durability-related properties of polypropylenefiber-reinforced concrete," Sustainability, vol. 12, no. 2, p. 549, 2020.

[14] W. K. Chen and Q. F. Liu, "Moisture and multi-ions transport in concrete under drying-wetting cycles: a numerical study," Journal of Hydraulic Engineering, vol. 52, no. 5, pp. 622-632, 2021.

[15] L.-x. Mao, Z. Hu, J. Xia et al., "Multi-phase modelling of electrochemical rehabilitation for ASR and chloride affected concrete composites," Composite Structures, vol. 207, no. Jan, pp. 176-189, 2019.

[16] C. L. Zhang, W. K. Chen, M. Song, Š. Branko, and Q. F. Liu, "Numerical investigation of external sulfate attack and its effect on chloride binding and diffusion in concrete," Construction and Building Materials, vol. 285, no. 122806, pp. 117, 2021.

[17] J. Liu, L. Peng, and M. Lei, "A concrete chloride ion erosion model considering influence of linear distributed stress," J Cent South Univ (Natural Sci Ed, vol. 49, no. 2, pp. 393-400, 2018.

[18] J. Xiao, J. Ying, V. W. Y. Tam, and I. R. Gilbert, “Test and prediction of chloride diffusion in recycled aggregate concrete," Science China Technological Sciences, vol. 57, no. 12, pp. 2357-2370, 2014.

[19] Q.-f. Liu, Z. Hu, X.-y. Lu, J. Yang, I. Azim, and W. Sun, "Prediction of chloride distribution for offshore concrete based on statistical analysis," Materials, vol. 13, no. 1, pp. 174-190, 2020.

[20] T. Chen, "Intelligent prediction of durability life of underground concrete lining structure," Journal of Basic Science and Engineering, vol. 18, no. 5, pp. 784-791, 2010.

[21] Q. F. Liu, I. M. Farjad, J. Yang, X. Y. Lu, P. Zhang, and R. Momina, "Prediction of chloride diffusivity in concrete using artificial neural network: modelling and performance evaluation," Construction and Building Materials, vol. 268, no. 121082, pp. 1-14, 2021.

[22] H. Qiao, B. Zhu, Q. Feng, N. Desire, and J. Dong, “Accelerated life testing of reinforced concrete based on performance degradation and reliability modeling," Journal of Materials in Civil Engineering, vol. 30, no. 5, Article ID 04018071, 2018.

[23] H. Qiao, X. Guo, and B. Zhu, "Accelerated life test of concrete under multiple factors based on three-parameter weibull distribution," Mater Reports, vol. 33, no. 04, pp. 639-643, 2019.

[24] A. Sanhueza, V. Leiva, and N. Balakrishnan, “The generalized birnbaum-saunders distribution and its theory, methodology, and application," Communications in Statistics - Theory and Methods, vol. 37, no. 5, pp. 645-670, 2008. 
[25] Z. Liu, X. Li, and D. Deng, "Comparison of paste damage in evaporation zones of portland cement paste and calcium sulphoaluminate cement paste," Journal of the Chinese Ceramic Society, vol. 44, no. 8, pp. 1173-1177, 2016.

[26] Z. W. Birnbaum and S. C. Saunders, "A new family of life distributions," Journal of Applied Probability, vol. 6, no. 2, pp. 319-327, 1969.

[27] M. E. Orchard and G. J. Vachtsevanos, "A particle-filtering approach for on-line fault diagnosis and failure prognosis," Transactions of the Institute of Measurement and Control, vol. 31, no. 3/4, pp. 221-246, 2009.

[28] S. C. Xiong, J. Y. Lu, Y. F. Zheng, and D. L. Zeng, "Lifetime prediction of metallized film capacitor based on particle filter," High Voltage Engineering, vol. 44, no. 7, pp. 2378-2384, 2018.

[29] G. M. Cordeiro and A. J. Lemonte, "The -birnbaum-saunders distribution: an improved distribution for fatigue life modeling," Computational Statistics \& Data Analysis, vol. 55, no. 3, pp. 1445-1461, 2011. 